\title{
As referências utilizadas pelos cadetes da Academia da Força Aérea para o exercício da liderança: o que eles falam sobre isso
}

\author{
Eliana Prado Carlino ${ }^{1}$
}

\section{Resumo}

Esta pesquisa intenciona investigar alguns aspectos da aprendizagem da liderança pelos cadetes da Academia da Força Aérea (AFA), ou seja, quais são as referências nas quais eles se apoiam ao exercer a liderança com os cadetes mais modernos. Para tratar metodologicamente dessa questão, fizemos uso de narrativas, já coletadas em momento anterior, nas quais foram ouvidos cadetes que, em 2016, pertenciam ao quarto Esquadrão e atuaram como adaptadores dos estagiários recém chegados à AFA no ano de $2015^{2}$. A questão utilizada em nossa investigação foi em relação às quais eram as referências ou os pontos de apoio (leituras, experiências, lideranças anteriores etc.) que esses cadetes utilizavam ao exercer a função de líderes durante o seu processo formativo. As respostas foram analisadas com base num referencial teórico apoiado no conceito de enunciação, de Bakhtin, por articular a ideia de que o coletivo e o social estão imbricados no individual, além de conceitos de liderança trabalhados por diversos autores. Também utilizamos o referencial teórico de Donald Schon e sua contribuição sobre a formação de profissionais reflexivos. Os dados apontam para o fato de que não há muitos marcos teóricos que embasam o exercício de liderança pelos cadetes na AFA e faz-se necessário promover experiências de formação num contexto de reflexão que articule aspectos de conhecimentos teóricos com aspectos práticos.

Palavras-chave: Liderança. Narrativas. Reflexão.

\footnotetext{
1 Doutora em Educação pela Universidade Federal de São Carlos, mestre em Educação pela Universidade Metodista de Piracicaba e bacharel em Psicologia pela Universidade Estadual Paulista Júlio de Mesquita Filho. Professora Titular da AFA. E-mail: ecarlino@bol.com.br.

${ }^{2}$ Número do Parecer consubstanciado do Comitê de Ética em Pesquisa: 3.507.668.
} 


\section{Contextualizando a pesquisa}

Este trabalho pretende dar continuidade a um projeto cujo foco central é o processo de aprendizagem da liderança pelos cadetes da Academia da Força Aérea (AFA).

Ao trabalhar durante muitos anos com o tópico liderança, na disciplina Psicologia Organizacional, junto ao $1^{\circ}$ Esquadrão, nos quadros de Aviação, Intendência e Infantaria, muitas questões foram nos inquietando. A primeira delas se refere ao fato de, em muitas situações, os alunos do primeiro ano identificarem algumas práticas observadas e vivenciadas por eles, por parte das chefias e lideranças, como um tanto arbitrárias e algumas vezes, sem sentido, práticas essas que eles reproduzem posteriormente.

Como os cadetes do primeiro ano estão chegando à organização militar e iniciando seu processo de socialização, muitas coisas, realmente, não são de fácil entendimento para eles; mas, com o passar do tempo, muitas razões e motivos das condutas militares tornam-se mais compreensíveis. No entanto, podem ocorrer muitas coisas que são arbitrárias, mesmo, ou sem sentido.

A segunda razão é o fato de, apesar de a liderança ser um tema trabalhado durante sua formação, já que é a atividade fim do cadete da Aeronáutica, pois, é missão da Academia da Força Aérea "formar oficiais em condições de se tornarem líderes de uma moderna Força Aérea" (BRASIL, 2014), esse conteúdo parecer pouco apropriado pelos cadetes quando estão nessas funções, nas quais têm que exercer a liderança.

Apercebemo-nos, assim, que, quando esses primeiros esquadrões chegam ao $3^{\circ}$ e $4^{\circ}$ anos, eles repetem muito dos modelos que tanto criticaram. E aquilo que, outrora, foi percebido como sem sentido ou arbitrário, acaba sendo reproduzido da mesma forma, quase que automaticamente, sem reflexão e sem tentativas de buscar outras formas de praticar essa liderança ou de exercer sua influência sobre outros sujeitos.

Isso tem nos levado a indagar como se dá esse processo de aprendizagem da liderança dentro da Academia da Força Aérea e quais são os pontos de apoio para os cadetes ou as referências que eles buscam ao exercê-la.

Iniciamos, assim, em 2016, uma primeira investigação dessa temática, colocando nosso olhar sobre esse fenômeno. Numa primeira produção teórica sobre o tema e fruto de pesquisa de campo já realizada, procuramos apreender quais eram as concepções que os cadetes tinham sobre liderança. 
Para isso, ouvimos os cadetes do terceiro e quarto Esquadrões, que atuaram como adaptadores $^{3}$ do primeiro Esquadrão nos anos de 2015 e 2016, no que se refere aos vários aspectos relacionados ao fenômeno da liderança.

Trabalhamos com um roteiro de questões que norteou a narrativa dos cadetes, indagando o que eles entendiam por liderança; se eles percebiam diferenças e quais eram elas, entre a sua vivência como estagiário e a sua atuação como adaptador; quais referências eram buscadas por eles quando estavam no exercício de alguma forma de liderança (autores, livros, pessoas, líderes ou chefes que tiveram); de quais experiências, conhecimentos ou conteúdos eles se utilizavam nesse processo; em quais contextos da AFA eles consideravam que aprendiam sobre liderança, entre outras questões.

Os cadetes, sujeitos desta pesquisa já tiveram vários contatos com o tema abordado, seja em disciplinas como Psicologia Organizacional, Gestão de Pessoas, em instruções dadas pela Seção de Doutrina, além do Curso de Padronização de Instrutores (CPI), do qual participaram antes de atuarem na adaptação dos novos cadetes (estagiários) recém chegados à Academia. Nesse CPI, os cadetes participam de várias instruções, com o objetivo de preparálos e orientá-los para a execução específica dessa tarefa de adaptação dos estagiários.

Sendo assim, num primeiro momento da pesquisa fizemos um "recorte" inicial no qual procuramos apreender como o cadete entendia a liderança. Contudo, neste artigo será focada outra questão do mesmo roteiro, que examina as referências (teóricas ou não) buscadas pelos cadetes para exercerem a função de líderes.

Alguns cadetes têm se debruçado sobre o tema liderança em seus trabalhos monográficos, apontando novas possibilidades e modelos. Andrade (2018) e Vargas (2018) abordam, respectivamente, tópicos como "Liderança Full Range no Corpo de Cadetes da Aeronáutica" e "O exemplo como um dos fatores determinantes na aprendizagem da liderança na AFA". Andrade (2018) aponta o modelo de Liderança Full Range como alternativa de um modelo a ser incorporado na teoria e na prática da formação dos futuros oficiais da Força Aérea Brasileira.

Esse modelo pressupõe a atuação do líder de diferentes formas, de acordo com diferentes circunstâncias e de acordo com a resposta dada pelo liderado. Nesse sentido, o líder pode transitar desde uma faixa de liderança Laissez-faire, passando pela transacional até chegar ao modelo transformacional.

${ }^{3}$ Adaptadores são os cadetes mais antigos que recebem os estagiários do primeiro ano e fazem a sua adaptação à vida militar. O Estágio de Adaptação Militar (EAM) tem como objetivo adaptar o aluno recémchegado aos valores e peculiaridades da vida numa organização militar. 
Em suma, procura-se, com essa teoria, mostrar que a liderança é um fenômeno dinâmico e que depende de vários fatores, tanto externos quanto internos, para que atinja os objetivos a que se propõe. Além disso, deixa-se de lado a ideia de que o líder deve agir somente de uma forma para cumprir as tarefas para as quais foi designado. Adota-se, a partir desse momento, uma nova concepção de liderança, mais moderna e atualizada (ANDRADE, 2018, p. 24).

No trabalho de Vargas (2018) a intenção é mostrar a força dos modelos/exemplos na aprendizagem do cadete sobre a liderança.

O cadete, por passar um tempo considerável em formação na AFA, totalizando pelo menos quatro anos, acaba, em muitos momentos de sua rotina, tendo um contato indireto com militares e instrutores da unidade. Esse contato indireto muitas vezes gera observação de comportamentos e condutas, possibilitando o surgimento de críticas, avaliações e concepções que o cadete desenvolve a respeito do que seja a liderança (VARGAS, 2018, p. 10).

Dessa forma, o autor do trabalho monográfico, apoiado nas ideias de Bandura (1977, apud HERMETO e MARTINS, 2012) sobre aprendizagem social, conclui que o exemplo é uma contribuição significativa para o aprimoramento da liderança do futuro oficial da Força Aérea Brasileira. Entretanto, apesar da influência dos modelos de comportamento, "que funcionam como exemplos - oferecidos ao cadete por meio do contato direto ou indireto com as figuras que desempenham papéis de liderança" (VARGAS, 2018, p. 11), não se pode desconsiderar a necessidade de aprimorar essa aprendizagem com leituras e estudos científicos desenvolvidos, inclusive, por aqueles envolvidos no processo de formação dos cadetes da Força Aérea.

Também indagamos se essa aprendizagem baseada em modelos é suficiente quando pensamos num programa de formação para futuros líderes; afinal, o exemplo que o cadete considera adequado para ser imitado está fundamentado em que tipo de aprendizagem? E que tipo de embasamento científico ou de literaturas seria importante e necessário para o aprimoramento desse processo? Essas literaturas aparecem nas narrativas dos cadetes?

[...] eu me espelho muito na liderança que meus pais exerciam comigo, assim, de como eles faziam com que eи cumprisse o que eles queriam que eu cumprisse [...] eu revelo que eu não tenho muito interesse em relação à leitura; eu li "O monge e o executivo”; eu li “A arte da guerra”, mas são livros que são bastante abrangentes $e$ nada que eu possa dizer que eu me aprofundei na questão da liderança. Mas... é com relação aos exemplos também que a gente tem na rotina, que a gente percebe; de não cometer erros que a gente não gostou que cometeram com a gente (cadete 2).

...embora tenha uma série de orientações doutrinárias, falta um marco firme em relação à teoria. Às vezes, o instrutor chega e fala: "olha, esse tipo de liderança é isso, esse tipo de liderança é isso, esse tipo de liderança é isso, ponto. Uma semana depois chega outro instrutor que ensina outro autor que define de forma contrária as mesmas coisas [...] e de onde ele tirou? Não sei, exatamente (cadete 5). 
A gente acaba se baseando em outro cadete e outros oficiais que a gente conheceu ao longo dos anos de formação. Eu me baseio muito em um cadete específico, que foi da liderança,... ele foi adaptador quando eu era primeiro ano; foi da liderança quando eu era segundo e um ou outro oficial que eu olho e acho uma referência, até um pouco da vida pessoal, também (cadete 5).

não existe um manual que delineie ali tudo o que você deve falar, tudo o que você deve passar, não existe [...] A gente tem como referência, às vezes, o nosso líder de Esquadrão naquela época, o que ele passou e a gente compreendeu como certo; experiências passadas durante as aulas doutrinárias... (cadete 6)

Além dos modelos a que eles se referem, há menção a algumas leituras feitas. Entre elas, a mais citada é o livro "O Monge e o Executivo", lido por $50 \%$ dos cadetes do $4^{\circ}$ Esquadrão que participaram da pesquisa, seguido por "Inteligência Emocional" (de Daniel Goleman), lido por $25 \%$ dos cadetes pesquisados. Além desses, apareceram outras leituras feitas, porém referidas apenas uma vez, a saber, "A arte da guerra", "A arte de ser chefe", "Liderança servidora", "Liderança situacional” (de Hersey e Blanchard), "Líder 360”.

Eu lembro que eu li, sim, alguns livros; posso citar pra senhora aqui "O monge e o executivo", foi um livro que me agregou bastante; "A arte de ser chefe", tem muitas questões legais naquele livro também. Procurei um pouco de conhecimento voltado à psicologia, então, "Inteligência emocional", "linguagem corporal”, é um livro que еu achei muito interessante... (cadete 6).

A partir desta questão utilizada no roteiro de entrevistas com os cadetes, "quando você está no exercício de alguma liderança, quais as referências que você busca; onde você se apoia para exercitá-la? (autores, livros, experiências anteriores, líderes que você teve etc.), interessou-nos saber quais são as referências teóricas ou os pontos de apoio que eles buscam ao exercer a liderança com os cadetes mais modernos e como refletem sobre isso.

Os dados obtidos e apontados num primeiro artigo mostraram que a visão de liderança que eles têm é muito aproximada de uma visão do senso comum, e que, apesar de uma capacidade de reflexão sobre a sua realidade, o cadete não encontra espaço propício, no seu âmbito de formação, para narrar tais vivências, o que pode impedir a tomada de consciência dessas situações assim como a possibilidade de ressignificá-las.

\footnotetext{
[...] quando acontece alguma situação, eu tento refletir bastante e lembrar... como aqui na AFA as pessoas passam, praticamente todas, as mesmas coisas que a gente passa, eu penso em lembrar como era quando eu estava naquela situação e também busco opinião de outras pessoas, entendeu? Os que hoje tem atitudes coerentes, pessoas que eu julgo que são mais maduras (cadete 1).
}

Muitas são as situações nas quais o cadete pode exercitar a liderança. Critérios como desempenho acadêmico e militar são utilizados no momento de designar os cadetes que vão auxiliar e conduzir os esquadrões mais modernos a alcançar níveis de desempenho desejados pela organização. Assim, esses cadetes mais antigos se tornam líderes de curso, de esquadrão, 
de esquadrilha, de elemento, dentre outros; e também adaptadores. Essas funções, indubitavelmente, auxiliam os cadetes designados a exercerem e desenvolverem as suas atribuições de liderança.

Diversas são as perspectivas pelas quais podemos estudar e procurar compreender esse fenômeno; vários são os olhares possíveis e as vertentes teóricas que, ao longo do tempo procuraram, e ainda procuram, explicá-lo.

Muitos autores trabalharam no sentido de definir o conceito de liderança (BERGAMINI e CODA, 1997; ROBBINS, 2004; GOLEMAN, 2006; BERGAMINI, 2009; VIZIOLI e CALEGARI, 2010; ROBBINS; JUDGE; SOBRAL, 2010), mas, neste artigo, destacamos o conceito de Moura (2008), para quem liderança significa "um processo de influência sobre as cognições e os comportamentos de um conjunto de pessoas, visando-se alcançar uma meta preestabelecida" (MOURA, 2008, p. 43).

Influenciar cognições e comportamentos significa influenciar modos de pensar e de agir. Diríamos, ainda, que implica também atuar sobre modos de sentir. E, por ser um processo, depende da atuação não apenas do líder, mas de outros elementos presentes na relação e que devem ser considerados ao se conceituar esse fenômeno (MOURA, 2008), como os liderados, e a própria organização. Desse modo, liderança implica um fazer coletivo, daí a necessidade de pensar no líder também a partir da perspectiva dos liderados.

Em trabalhos relativos à discussão sobre o fenômeno da liderança, muito se tem falado sobre autoliderança, autodisciplina e autoconhecimento (PAIVA, 2008); sobre aspectos inconscientes que atuam nos grupos de trabalho (MOSCOVICI, 2008); sobre o não verbal nesses grupos; sobre resiliência e habilidades inter e intrapessoais (ROBBINS, 2004). Dessa maneira, há uma enorme contribuição dos fatores emocionais para que o sujeito seja ou não bem sucedido em seu trajeto profissional.

Os aspectos cognitivos não podem ser considerados os mais importantes na abordagem do tema, já que estar à frente de um grupo como alguém que vai mobilizar e influenciar comportamentos, cognições e afetos requer conhecimento sobre elementos não palpáveis que estão imbricados nessas relações. Moscovici (2008) afirma que a liderança é, acima de tudo, um processo interpessoal demasiadamente complexo que não se limita a aspectos unicamente tangíveis.

Desse modo, estamos imersos num território rico em questões que dizem respeito ao processo formativo docente e discente e neste momento, nosso olhar está voltado para o cadete e seu processo de constituição como aprendiz, como sujeito, como cidadão e como profissional e futuro líder da Força Aérea Brasileira (FAB). 


\section{Trato metodológico}

Assim, do lugar que ocupamos e ao pensar sobre essas questões e sobre os dados coletados, trazemos o referencial teórico de Donald Schon para contribuir com nossas considerações a respeito de alguns aspectos do processo de formação do cadete da AFA.

Donald Schon é um teórico que, na década de 90, trouxe para o contexto acadêmico grandes contribuições sobre a formação de profissionais reflexivos, principalmente no que diz respeito à formação docente, ainda que seus estudos não se refiram unicamente aos profissionais da educação, mas digam respeito a profissionais de diferentes áreas. Foi ele quem fez a crítica ao modelo da racionalidade técnica, além de propor a reflexão como parte do processo de trabalho profissional.

Em relação à formação de professores, tem sido considerada a ineficácia de um certo modelo - o da racionalidade técnica - que entende o professor como um técnico, cuja responsabilidade é aplicar conhecimentos e teorias científicas no sentido de solucionar os problemas oriundos da prática pedagógica. Sobre a reflexão, a filosofia a considera como "o ato ou o processo por meio do qual o homem considera suas próprias operações. Entretanto, vários são os sentidos historicamente atribuídos ao termo pelas diferentes filosofias" (MATOS, 1998, p. 287).

Dewey, já no início deste século, distinguiu, no trabalho do professor, a ação rotineira (guiada por impulso, tradição e autoridade) da ação reflexiva - "a que implica uma consideração ativa e cuidadosa daquilo em que se acredita ou que se pratica, iluminada pelos motivos que a justificam e pelas consequências a que conduz" (Geraldi, Messias e Guerra, 1998, p.248).

Assim, o foco principal deste trabalho continua sendo sobre a aprendizagem da liderança, utilizando as narrativas já gravadas nas várias entrevistas feitas com cadetes do Terceiro e Quarto Esquadrões, sobre suas percepções a respeito desse fenômeno. Queremos ressaltar que essas percepções contêm muito do que está no imaginário social sobre o tema contribuindo com a formação das idéias existentes sobre ele.

Moura (2008) afirma que há uma grande influência de suposições sobre o fenômeno da liderança, constituindo um imaginário social nesse campo, o que coloca como urgente a realização de mais pesquisas nessa área. E, no caso da liderança militar, "observa-se a mesma lacuna - a falta de um programa de pesquisas atualizadas que visem acompanhar no campo os efeitos dos empreendimentos de seleção/capacitação de líderes” (MOURA, 2008, p. 46). 
Nosso enfoque metodológico continuará fazendo uso das narrativas ou entrevistas autobiográficas feitas com os cadetes a respeito das percepções que eles têm sobre sua prática ao exercitar a liderança em relação a outros cadetes. Portanto, esta investigação será produzida a partir de um corpo de dados já coletado e com base no referencial apoiado no conceito de enunciação de Bakhtin (2004). A questão a ser utilizada para as análises será: “quando você está no exercício de alguma liderança, quais as referências que você busca; onde você se apoia para exercitá-la? (autores, livros, experiências anteriores, líderes que você teve etc.).

A abordagem teórico metodológica aqui utilizada pressupõe que existe uma interrelação entre uma história de vida com várias outras histórias, evidenciando a presença do coletivo nas relações estabelecidas cotidianamente (SOUZA e KRAMER, 1996).

Também buscamos em Bakhtin (2004) e em sua visão sobre a linguagem como constitutiva do humano, elementos para que pudéssemos apoiar nossa ideia de que o coletivo e o social estão imbricados no individual.

Em toda enunciação, por mais insignificante que seja, renova-se sem cessar essa síntese dialética [...] entre a vida interior e a vida exterior. [...] Cada palavra se apresenta como uma arena em miniatura onde se entrecruzam e lutam os valores sociais de orientação contraditória. A palavra revela-se, no momento de sua expressão, como o produto da interação viva das forças sociais (BAKHTIN, 2004, p. 66).

Ao falar sobre enunciação estamos nos referindo ao produto do ato de fala, mas não como um ato individual, no sentido literal do termo, nem apenas como resultado das condições psicofisiológicas do sujeito que fala, e sim considerando a sua natureza social (Bakhtin, 2004).

O referencial teórico desta pesquisa utiliza uma concepção de linguagem que, correlacionando a instância individual e a social, o psíquico e o dialético, a vida interior e a exterior, traz à tona conceitos como o de enunciação, mostrando que a palavra ao ser expressa contém em si um jogo intenso de forças sociais; não é una; não é inequívoca e nem transparente.

No contexto das interações, os sentidos atribuídos ao conceito de liderança são marcados pelas condições concretas de vida, das quais participa cada pessoa que produz sua enunciação e se posiciona sobre esse fenômeno.

A partir disso, decorre também a ideia de que, ao falarmos de um único sujeito estamos falando e retratando a realidade de muitos outros; sujeitos que, mesmo sendo singulares em sua subjetividade, participam de um mesmo cenário ou arena social, o que os torna muito semelhantes também. 
Fizemos um "recorte" com as narrativas de oito sujeitos que foram cadetes em 2016, pertenciam ao quarto Esquadrão e, à época, ocupavam funções de liderança, sendo parte da Cadeia de Liderança do Corpo de Cadetes. O critério para a escolha desses sujeitos se deu pelo fato de terem participado como cadetes adaptadores em 2015 e por serem mais antigos no exercício e na vivência como líderes. Foram duas cadetes mulheres e seis cadetes homens, na faixa etária entre 22 e 25 anos, pertencentes aos três quadros (Aviação, Intendência e Infantaria).

\section{Liderança e reflexão}

Para Schon (apud. Alarcão, 1996), existem instâncias no processo reflexivo, as quais são: conhecimento na ação, que significa o conhecimento demonstrado pelos profissionais enquanto executam sua ação; reflexão na ação, que é aquela que ocorre simultaneamente com a ação; reflexão sobre a ação, sendo esta a que ocorre retrospectivamente ao reconstruirmos mentalmente a ação e finalmente, reflexão sobre a reflexão na ação, momento que ajuda a determinar e decidir as ações futuras (CARLINO, 2000, p.53).

Ainda de acordo com Schon (apud CAMPOS e PESSOA, 1998), uma base epistemológica que supere a racionalidade técnica só pode ser produzida a partir da reflexão que os profissionais fazem tomando como base os problemas práticos que surgem no seu cotidiano.

Ao estudar a atuação dos profissionais (não necessariamente professores), Schon distingue entre reflexão na ação e sobre a ação como formas de desenvolvimento profissional. No primeiro caso, os profissionais refletem no decurso da própria ação sem a interromperem, embora com brevíssimos instantes de distanciamento. Chamemo-lhe um diálogo com a própria situação. No segundo caso, reconstroem mentalmente a ação, a posteriori, para a analisarem. Em ambas as situações, a reflexão cede normalmente lugar à reestruturação da ação (ALARCÃO, 1996, p.176).

Assim, podemos entender reflexão como

uma perscrutação ativa, voluntária, persistente e rigorosa daquilo em que se julga acreditar ou daquilo que habitualmente se pratica, evidencia os motivos que justificam nossas ações ou convicções e ilumina as consequências a que elas conduzem. Eu diria que ser-se reflexivo é ter a capacidade de utilizar o pensamento como atribuidor de sentido (ALARCÃO, 1996, p. 175).

A fala de um cadete nos mostra um pouco dos referenciais tácitos, que embasam muito das nossas ações, e que é aquele conhecimento que está presente na atuação dos profissionais, ainda que sobre eles não se tenha pensado previamente (Alarcão, 1996). Segundo Polanyi 
(apud Schon, 1992, p. 82), é designado como "conhecimento tácito" aquele que é "espontâneo, intuitivo, experimental, conhecimento quotidiano".

[...] Só que pra mim não é assim que funciona: 'ah, vou estudar aqui a liderança transformacional, agora vou ser transformacional, agora vou ser transacional'. Isso não passa na sua cabeça quando você está liderando; é importante você ter uma base ou saber que existem partes teóricas por trás daquilo; então eu procuro também ver experiências assim que eu gosto, que se passaram comigo, que eu vi outras pessoas passarem; acho que isso é muito importante, assim, a gente passa, nesses quatro anos de Academia, por situações que a gente gostou ou não gostou, coisas que marcaram (cadete 7).

A fala seguinte aponta como um dos cadetes, ao pensar sobre o exercício da liderança, procura organizar sua ação:

Eu, sinceramente, no início do ano eu não sabia muito bem como é que eu iria exercer minha liderança, como é que eu poderia fazer isso, mas eu pensava que no $2^{\circ}$ ano a gente ia fazer isso, no $3^{\circ}$ ano a gente ia fazer isso, porém no $4^{\circ}$ ano quando tu está numa posição: "não, agora você é líder de uma esquadrilha, como é que eu vou fazer isso?" Dai o que eu tentei fazer, né? Eu tracei meu objetivo e todas as minhas ações durante o ano foram pra que eu conseguisse alcançar esse objetivo (cadete 1).

A ausência de pesquisas no âmbito da liderança militar também é sentida por eles, o que tem movido alguns para esse campo de investigação.

Quando eu estudo liderança eu percebo que, realmente, tem pouca parte de liderança militar e mesmo da liderança eu noto que... às vezes... coisas meio óbvias, assim: 'você tem que ser um cara responsável, tem que avaliar a necessidade do seu liderado, você tem que inspirar ele...' isso é óbvio que você tem que fazer isso, mas, como fazer isso? (cadete 7 ).

Acho que a própria prática ela me ensinou bastante, só que eu não podia aprender só na prática, né, daí.. acho que o primeiro passo que tem é o exemplo, querendo ou não, eu olhava para o cadete mais antigo e tentava copiar algumas coisas: 'poxa, numa situação dessas, ele fez isso, vou tentar fazer também'. Só que eu vi que isso também não era o suficiente e aí foi quando eu tive um insight para fazer a minha monografia sobre isso porque [...] eu ia juntar uma curiosidade que eu tinha, de como atuar, num meio que eu iria ter de pesquisa (cadete 8).

Para Dewey (apud ALARCÃO, 1996), diferentemente de uma ação rotineira, geralmente baseada em impulso, costume ou tradição, a reflexão está baseada na "vontade, no pensamento, em atitudes de questionamento e curiosidade, na busca da verdade e da justiça [...] e une cognição e afetividade num ato específico, próprio do ser humano" (ALARCÃO. 1996, p. 175).

Fiquei muito impressionado em descobrir que a gente faz muita coisa errada; tem certas atitudes assim, que a gente toma aqui... eu passei pelo processo e agora estou fazendo o processo, na medida do que me é possível. [...] e eu vi que a gente comete muitos erros (cadete 3 ).

Ao repensar suas ações, alguns consideram que há erros nas atitudes que desenvolvem em relação aos outros e se propõem mudanças que só se tornam possíveis a partir de novas possibilidades de leitura da realidade, o que advém com a busca de novos conhecimentos. 
Aí comecei a correr atrás de informação, de procurar. [...] Eu continuei buscando mais informações no meio militar, no meio civil, e procurei o curso da FGV; descobri que o gestor de projetos, ele é um líder lá no meio civil. Aí eu falei: 'parece bastante com o que a gente faz, né?' (cadete 3).

Por isso a importância da reflexão não ser considerada como um fim em si mesma, tendo cuidado com o termo que

já virou jargão e tem sido usado na literatura de modo pouco criterioso e vago, gerando mistificações, slogans e compreensões ambíguas; portanto, a reflexão não pode ser entendida independente do conteúdo da própria reflexão, do contexto em que ela é feita e das interações nas quais ela se dá (CARLINO, 2000, p. 52).

E no exercício de refletir sobre a prática, o importante é não descuidar de que essa ação, "ao mesmo tempo em que deve estar voltada para a própria prática do profissional - suas crenças, percepções, valores e entendimentos sobre o seu fazer - deve voltar-se também para o contexto em que essa prática é produzida, e que é por isso também, um determinante dela". (CARLINO, 2000, p. 53)

Lembremos aqui que as narrativas ou relatos procuram refletir o mundo vivido para, a partir dele, derivar um sentido; este sentido é construído coletivamente, pois não é resultado apenas da consciência de quem faz o relato e nem apenas da consciência do pesquisador (PINEAU, 2006). Bertaux (apud. PINEAU, 2006, p.340) afirma que "há relato de vida desde que haja descrição na forma de narrativa de um fragmento de experiência vivida".
É uma coisa que a gente vai reproduzindo, que se tem como correta, como assertiva, e na verdade não é nada assertivo. Você pontuar quem é, 'dar nome ao boi', ou então, por exemplo, está todo mundo sentado, que é o que acontecia na minha época, e você 'pipocar' o cara ali e ele ficar em pé e você chamar a atenção na frente dos outros, isso eu acho desnecessário; agora você abordar o erro que essa pessoa fez, e de modo geral, é muito válido, eu acho que esse é o 10! E uma coisa que falta, professora, é elogiar. [...] atua-se no erro; então você vive martelando o erro, então, o cara errou, você 'bate'; errou, você 'bate' (cadete 3).

Nesse exemplo, como afirma Schon, o sujeito reflete, a partir de suas leituras, da experiência vivida e do conhecimento adquirido, sobre a ação, porque ele faz isso retrospectivamente ao reconstruir uma determinada ação de modo mental e ainda vemos a reflexão sobre a reflexão na ação, pois, ao expressar seu pensamento e rever conceitos como reforço positivo ou punição ${ }^{4}$, isso lhe ajuda a reorganizar e decidir suas ações futuras.

Trabalhar nessa perspectiva metodológica nos faz acreditar que, ao contar um episódio no qual o sujeito se insere, ele pode se rever, e isso pode ajudar no seu aspecto formativo, considerando o que já disse Catani (1998) sobre a possibilidade que o sujeito encontra de, ao contar-se, poder iniciar uma reflexão sobre seus próprios processos formadores. Isso é o que

\footnotetext{
${ }^{4}$ Conceitos trabalhados numa concepção behaviorista do comportamento humano que relacionam o 'elogio' ao reforço positivo e a 'atuação no erro' à punição.
} 
tem feito as pesquisas qualitativas tornarem-se uma alternativa para a sua formação, ainda que essa não seja a intenção essencial, pois

\begin{abstract}
ao mesmo tempo em que o sujeito organiza suas ideias para o relato - quer escrito, quer oral - ele reconstrói sua experiência de forma reflexiva e, portanto, acaba fazendo uma autoanálise que lhe cria novas bases de compreensão de sua própria prática. A narrativa provoca mudanças na forma como as pessoas compreendem a si próprias e aos outros (CUNHA, 1997, p.188).
\end{abstract}

Por esse motivo, pensarmos que o material produzido a partir dessas narrativas, além de ser nosso recurso metodológico na investigação, pode ser também um instrumento utilizado na própria formação do cadete, ou seja, em situações de ensino. Acreditamos, mesmo, que isso nos instigou com este trabalho, porque falamos muito pouco disso, pensamos muito pouco sobre esse fenômeno que é, praticamente, a atividade fim da Academia, ou seja, a liderança.

Talvez a coisa que eu acho que aqui na AFA é bem complicado de lidar é a questão do erro. Querendo ou não, quem toma a iniciativa aqui, se expõe bem mais e acho que deve ser o principal motivador de as pessoas se fecharem, então, por que eu vou ficar jogando isso aí pra minha responsabilidade e, se eu errar, ainda posso ficar preso?[...] Quando ele erra por tomar uma iniciativa que a gente chama de 'iniciativa torta' ou quando ele erra porque simplesmente ele foi negligente, então saber diferenciar... (cadete 8).

Ainda que os cadetes não tenham experiências como oficiais, eles têm a vivência como alunos, e sua aprendizagem sobre liderar já se iniciou muito antes dele adentrar a Academia da Força Aérea e continua durante seu processo de formação. E essas vivências merecem ser repensadas, questionadas e reelaboradas. Todos os cadetes têm experiências de liderança (não necesssariamente como líderes, mas como liderados) e, dessa forma, também elaboram conhecimentos sobre o que seja liderar.

Por isso, acreditamos como Zeichner (1995, p.130) que "temos de ter em conta as ideias anteriores e as regras que os alunos aliam à experiência e devemos ajudá-los a exteriorizá-las segundo concepções mais apropriadas.

\footnotetext{
Nesse livro que eu li, o foco foi a inteligência emocional e a definição de liderança, mesmo, focava bastante os aspectos de autoconhecimento, autogestão; ir até o subordinado, ir até o liderado para se aproximar e conhecer a realidade dele; é se posicionar como grupo e não como uma pessoa fora do grupo e que só cobra o rendimento, né? Aqui a gente é muito cobrado sempre a atingir resultados, e quando a gente falha, geralmente imputa isso ao outro (cadete 4).
}

Nesse sentido, se você sabe que a capacidade de ouvir é importante para o exercício da liderança porque os liderados apreciam saber que suas necessidades são compreendidas pelo "outro", é importante que, ao exercer a liderança você realize um exercício de autoavaliação, ao qual nem todos se dispõem. E, torna-se fundamental se perguntar: "naquele contexo, 
naquele momento como eu agi? Como eu atuei ali? Será que eu tive essa disponibilidade? Será que eu poderia ter ouvido mais?" E, nesse momento, também pensar o que significa ouvir o outro. E aí, então, você está refletindo sobre a ação, em como você poderia ter resolvido aquele conflito, aquela situação; é quando você pensa naquilo que fez e como o fez. E, neste instante, o referencial teórico é importante porque vai subsidiar essa reflexão

“A reflexão apresenta-se-me com uma dimensão formativa e uma dimensão pragmática. Quer isto dizer que aprofunda o nosso saber no que ele encerra de conhecimento e de capacidades e que, além disso, se traduz no nosso modo de agir" (ALARCÃO, 1996, p. 178, 179). Alarcão (1996) nos ajuda a entender que refletir tem como objetivo atribuir sentido a uma experiência, tendo em vista um maior conhecimento da situação e, consequentemente, uma atuação mais apropriada.

Isso aparece também na narrativa de um dos cadetes, ao dizer que

\begin{abstract}
Para o cadete a relação é mais direta - você estuda e você vai agir de acordo com o que você estuda, mas, na realidade, não é isso; você estuda, você age e aquilo que você estudou vai servir para você refletir sobre como você agiu e se aquilo é positivo ou não; isso, eu concordo plenamente que é fundamental... eu não digo que não é importante estudar; é fundamental estudar, sim, porque a prática só vai servir para alguma coisa se você tiver estudado, não adianta fazer a prática baseado em nada (cadete 7 ).

Na realidade, eu ainda não me encontrei numa coisa que eu estude sobre liderança que eu tenha gostado da opinião do autor [...] porque me incomoda um pouco quando eu pego assim, uma coisa sobre comportamento humano e tentam categorizar num quadradinho, assim, se você fizer isso, vai dar isso; não é bem assim que funciona (cadete 7).
\end{abstract}

É nessa tensão que se contrapõem a realidade e as antigas certezas, que procuram dar respostas finais para uma realidade tão particular, que somos levados a compreender que os paradigmas hegemônicos não fornecem respostas para todas as incógnitas que o cotidiano apresenta, pois a realidade sempre apresentará novas e complexas dificuldades" (CAMPOS e PESSOA, 1998, p. 184).

Isso se torna mais evidente quando os cadetes se posicionam da seguinte forma:

É uma coisa que eu percebi, o fato de eu copiar a liderança dos cadetes mais antigos ela está começando a ficar um pouco prejudicada, porque o tratamento está tendo que ser diferente com eles (com os mais novos). Hoje, acho que os cadetes que estão entrando eles entram muito mais fáceis a se frustrar [...] Acho que a pior coisa que tem [...] é você forçar essa nova leva que está entrando a fazer uma coisa que eles não entendem; acho que isso, para eles, é algo impensável, né? (cadete 8).

Mas, aprender a obedecer desse jeito, será que é o melhor jeito que tem? [...] mas até onde, isso, na carreira militar consegue ajudar ou prejudicar, na questão da formação? Isso é que é o diferencial (cadete 8). 
E o importante é que eles entendem que essa é uma busca que não se finaliza e não se esgota com a formação inicial.

[...] a questão é correr atrás, é você ler, procurar se informar mais; a prática em si, ela ajuda muito, [...] no momento em que você fica ali sem saber o que fazer, quando você corre atrás... aí para, pensa, raciocina, conversa com um, conversa com outro; aí termina que você aprende também, e, talvez, acho que seja o maior aprendizado que tenha, é a conversa entre a gente da liderança (cadete 8).

Eu acho que basicamente é isso, e o cara tem que correr atrás de informação também (cadete 3).

Então em parte eu me apoio nisso, no que eu aprendo na Divisão de Ensino e também eu li um pouco. [...] E eu procuro, baseado nisso (nos exemplos de outros líderes), e também comparado com o que eu estudo, com o marco teórico, balizar minhas ações nesse sentido... porque é muito complicado (cadete 7).

Com essas narrativas, foi-nos possível levantar alguns aspectos que servem como referência aos cadetes no seu exercício da liderança, entre eles, a liderança exercida pelos pais; as orientações doutrinárias, ainda que apontem a falta de um marco teórico mais definido; o exemplo de outros cadetes e oficiais, além do exemplo do líder de Esquadrão; algumas poucas leituras. Por outro lado, também muitos colocam não ter referências, ou pelo menos, não referências explícitas.

\section{Considerações finais}

Nesse trabalho que procurou verificar os sentidos produzidos sobre a liderança e apreender as referências utilizadas pelos cadetes no exercício dessa tarefa, cada cadete falou de um "lugar" (familiar, histórico, social) específico, e esses diferentes lugares determinaram as enunciações por eles produzidas. Por isso, cada enunciado tem relação com a vida, com a realidade, é diálogo com outros, é relação entre pessoas (relação que não é necessariamente física, mas é pressuposta). E é nessa heterogeneidade de valores, crenças, experiências, vivências que a construção de um conhecimento pode ser encaminhada.

Entretanto, nesses sentidos que circularam em meio às narrativas, ocorrem constatações ("eu revelo que eu não tenho muito interesse em relação à leitura"; "para mim não é assim que funciona"; "é uma coisa que a gente vai reproduzindo, que se tem como correta, como assertiva, e na verdade não é nada assertiva”); questionamentos ( "o instrutor chega e fala; 'é isso', mas de onde ele tirou?"); indagações ( "isso é óbvio que você tem que fazer isso, mas... como fazer isso?”; "não adianta fazer a prática baseado em nada”), caracterizando o trabalho que está em marcha, pois, segundo Bakhtin (2003, p. 301), “o 
enunciado se constrói levando em conta as atitudes responsivas, em prol das quais ele, em essência, é criado".

Por meio dos relatos, foi-nos possível refletir sobre a nossa própria atuação, tanto no aspecto pessoal como no profissional. Isso nos confirmou a ideia de que, nessa trajetória formativa do cadete, precisamos promover e possibilitar mais experiências em clima de reflexão, entendendo aqui a reflexão como uma ação planejada e intencional.

O ser reflexivo, na concepção aqui adotada, pode exigir certo esforço e ser laborioso pela falta de costume, ou mesmo, pela falta de antecedentes e de uma cultura que propicie e favoreça essa atitude; é preciso que haja a necessidade e o empenho na mudança, que sejamos estimulados a sermos reflexivos, que as metodologias utilizadas neste trabalho favoreçam uma postura reflexiva de nós próprios como professores.

Ao invés de olhar para as falas e concepções dos cadetes como produtos finalizados (análise do produto), procuramos compreendê-las como parte de um processo ininterrupto e ver suas falas como situadas e demarcadas social e historicamente (análise do processo). Desse modo, elas adquirem sentido dentro de um contexto abrangente, deixam de ser compreendidas como finalização de um processo de ensino e vão sempre suscitando respostas.

Ainda são muitas as incertezas e as dúvidas, pois elas se multiplicam num cenário cada vez mais complexo e singular, no entanto, acreditamos que as contribuições teóricas de Bakhtin e de Schon possam contribuir com o debate sobre a formação de líderes no contexto da Força Aérea Brasileira.

Esta é uma interlocução iniciada, porém não terminada ou concluída. Ao produzir determinadas narrativas, os cadetes expressam sua forma de pensar sobre o fenômeno da liderança. Essa forma de pensar pode, muitas vezes, contrariar certo sentido dominante ou até uma série de princípios e valores discutidos no contexto de aprendizagem do qual eles participam. Entretanto, essas suas enunciações incorporam dificuldades vivenciadas, sentimentos, emoções que envolvem as suas vidas e as suas rotinas.

Cada cadete, ao se posicionar sobre esse tema, elaborou sua fala a partir de uma perspectiva que é sua, particular, mas que também pode ser a de muitos outros, já que a enunciação é de natureza social, como afirma Bakhtin (2004).

Assim, a aprendizagem sobre a liderança vem se constituindo há muito tempo na vida desses sujeitos; afinal 
o objeto do discurso do falante, seja esse objeto qual for, não se torna pela primeira vez objeto do discurso em um dado enunciado, e um dado falante não é o primeiro a falar sobre ele. O objeto, por assim dizer, já está ressalvado, contestado, elucidado e avaliado de diferentes modos; nele se cruzam, convergem e divergem diferentes pontos de vista, visões de mundo, correntes (BAKHTIN, 2003, p. 299, 300).

Isso nos leva a indagar como essas ideias podem ser transformadas, modificadas, na medida em que, por meio de novas mediações, se fale sobre elas. O que pode ser criado de novo?

Queremos ressaltar que não é só o trabalho circunscrito à sala de aula, com determinados materiais ou textos (a visão do texto, do autor, do instrutor ou do professor), que vai demarcando as possibilidades na atribuição de sentidos, mas muitos outros em muitas outras instâncias vão contribuindo nesse processo que nunca se sabe exatamente aonde vai dar.

Ao assumir a concepção de linguagem que assumimos aqui, precisamos rever o processo por meio do qual a significação ocorre nas relações de ensino e também nosso próprio papel como interlocutores (e não transmissores) que possibilitam novos sentidos aos conceitos circulantes.

Consideramos as entrevistas realizadas para esta pesquisa como um espaço e momento de discussão bastante importante para a formação dos cadetes, porque propiciou-lhes entrar em contato com o tema da liderança de modo mais abrangente, produzindo reflexões que não ocorreriam de outro modo.

De qualquer maneira, tais questões não podem ser fechadas ou finalizadas, ainda que tratadas como "considerações finais". Pelo contrário, elas abrem infinitas possibilidades de investigação que podem, e muito, auxiliar no processo de (re)significação do fenômeno da liderança no âmbito militar. 


\section{Referências Bibliográficas}

ALARCÃO, I. Ser professor reflexivo. In: (org.). Formação reflexiva de professores: estratégias de supervisão. Porto: Porto Editora, 1996. p.170-189.

ANDRADE, G. F. Liderança Full Range no Corpo de Cadetes da Aeronáutica. 2018. 43f. Trabalho de conclusão de curso. Academia da Força Aérea. Pirassununga, 2018.

BAKHTIN, M. Estética da criação verbal. 4. ed. São Paulo: Martins Fontes, 2003.

Marxismo e filosofia da linguagem: problemas fundamentais do método sociológico na ciência da linguagem. 11. ed. São Paulo: Hucitec, 2004.

BERGAMINI, C. W. Liderança: administração do sentido. 2ed. São Paulo: Atlas, 2009.

BERGAMINI, C. W.; CODA, R. Psicodinâmica da vida organizacional: motivação e liderança. 2ed. São Paulo: Atlas, 1997.

BRASIL. Academia da Força Aérea. Proposta de planejamento estratégico Academia da Força Aérea 2015 - 2030, PPE-AFA. Pirassununga, 2014.

CAMPOS, S. de; PESSOA, V. I. F. Discutindo a formação de professoras e de professores com Donald Schon. In: GERALDI, C. M. G.; FIORENTINI, D.; PEREIRA, E. M. de A. (orgs.). Cartografias do trabalho docente : professor(a)-pesquisador(a). Campinas, SP: Mercado de Letras: Associação de Leitura do Brasil, 1998. p. 183-206.

CARLINO, E. P. Necessidades educacionais especiais e necessidades formativas de professores. 138f. Dissertação (Mestrado em Educação). Faculdade de Educação, Universidade Metodista de Piracicaba (UNIMEP), Piracicaba, 2000.

CATANI, D. B. Práticas de formação e ofício docente. In: BUENO, B. O.; CATANI, D. B.; SOUZA, C. P. de. (orgs.). A vida e o ofício dos professores: formação contínua, autobiografia e pesquisa em colaboração. São Paulo: Escrituras, 1998. p. 21-30.

CUNHA, M. I. da. Conta-me agora!: as narrativas como alternativas pedagógicas na pesquisa e no ensino. Rev. Fac. Educ., São Paulo, v.23, n.1-2, jan. 1997. p 185-195

GERALDI, C. M. G., MESSIAS, M. da G. M. e GUERRA, M. D. S. Refletindo com Zeichner: Um encontro orientado por preocupações políticas, teóricas e metodológicas. In: GERALDI, C. M. G., FIORENTINI, D. e PEREIRA, E. M. de A. (orgs.). Cartografias do trabalho docente: professor(a)-pesquisador(a). Campinas, SP: Mercado de Letras: Associação de Leitura do Brasil, 1998. p. 237-274.

GOLEMAN, D. O que faz um líder? In: Liderança: os melhores artigos da Harvard Business Review. Rio de Janeiro: Editora Campos/Elsevier, 2006.

HERMETO, C. M. e MARTINS, A. L. (tradutoras). O Livro da Psicologia. São Paulo: Globo, 2012. 
MATOS, J. C. Professor reflexivo? Apontamentos para o debate. In: GERALDI, C. M. G., FIORENTINI, D. e PEREIRA, E. M. de A. (orgs.). Cartografias do trabalho docente : professor(a)-pesquisador(a). Campinas, SP: Mercado de Letras: Associação de Leitura do Brasil, 1998. p. 277-306.

MOSCOVICI, F. A organização por trás do espelho: reflexos e reflexões. 3ed. Rio de Janeiro: José Olympio, 2008.

MOURA, W. Liderança nas organizações: o dilema do real e do aparente. In: Jornadas de Psicologia do Serviço de Seleção do Pessoal da Marinha, 2009, Rio de Janeiro. Serviço do Pessoal da Marinha - Jornadas de Psicologia - Coletânea de textos, 2008, v. 52, p.42-46.

PAIVA, L. E. R. O líder militar: uma visão pessoal. PADECEME. Rio de Janeiro, n.19, $3^{\circ}$ quadrimestre, 2008. p. 76-83.

PINEAU, G. As histórias de vida em formação: gênese de uma corrente de pesquisa-açãoformação existencial. Educação e Pesquisa, São Paulo, v.32, n.2, maio/ago. 2006. p.329-343.

ROBBINS, S. P. Fundamentos do comportamento organizacional. São Paulo: Pearson Prentice Hall, 2004.

ROBBINS, S. P. JUDGE, T. A.; SOBRAL, F. Comportamento organizacional. 14ed. São Paulo: Pearson Prentice Hall, 2010.

SCHÖN, D. 1992. Formar professores como profissionais reflexivos. In: NÓVOA, A. (org.). Os professores e sua formação. Lisboa: Publicações Dom Quixote. p. 79-93.

SOUZA, S. J. e KRAMER, S. Experiência humana, história de vida e pesquisa: um estudo da narrativa, leitura e escrita de professores. In: SOUZA, S. J.e KRAMER, S. (orgs.). Histórias de professores: leituras, escrita e pesquisa em educação. São Paulo: Ática, 1996. p. 13-42.

VARGAS, G. de A. O exemplo como um dos fatores determinantes na aprendizagem da liderança na AFA. 2018. 42f. Trabalho de conclusão de curso. Academia da Força Aérea. Pirassununga, 2018.

VIZIOLI, M. e CALEGARI, M. da L. C. Liderança: a força do temperamento. São Paulo: Pearson Prentice Hall, 2010.

ZEICHNER, K. M. A formação reflexiva de professores: idéias e práticas. Lisboa: Educa. 1993.

Novos caminhos para o practicum: uma perspectiva para os anos 90. In: NÓVOA, A. (coord.). Os professores e a sua formação. Lisboa: Dom Quixote, 1995. 


\title{
References used by Air Force Academy cadets for leadership: what they talk about
}

\begin{abstract}
This research is intended to investigate some aspects of Air Force Academy (AFA) cadets' learning of leadership, in other words, what references they rely on when leading with the most modern cadets. To address this methodologically issue, we used narratives, already collected earlier, in which were heard cadets who, in 2016, belonged to the fourth Squadron and acted as adptive people of the new AFA trainees in 2015. The question used in our investigation was what were the references or points of support (readings, experiences, previou leadership, etc.) that these cadets used when exercising the role of leaders during their training process. The answers were analyzed based on a theoretical framework supported by Bakhtin's concept of enunciation, for articulating the idea that the collective and the social are imbricated in the individual, as well as leadership concepts worked by several authors. We also use Donald Schon's theoretical framework and his contribution to the training of reflective professionals. The data points to the face that there are not many theoretical frameworks that support the cadet leadership exercise at the AFA and it is necessary to promote training experiences in a context of reflection that articulates aspects of theoretical knowledge with practical aspects.
\end{abstract}

Keywords: Leadership. Narratives. Reflection. 